\title{
The voltammetric electrooxidation of glucose and glucose residues formed on electrodispersed platinum electrodes in acid electrolytes*
}

\begin{abstract}
A.M. Castro Luna, A.E. Bolzán, M.F. de Mele and A.J. Arvia
Instituto de Investigaciones Fisicoquímicas Teóricas y Aplicadas (INIFTA), Facultad de Ciencias Exactas, Universidad Nacional de La Plata, Sucursal 4, Casilla de Correo 16, (1900) La Plata, Argentina

Abstract - The voltammetric electrooxidation of glucose and glucose residues on electrodispersed platinum electrodes in $0.5 \mathrm{M} \mathrm{H}_{2} \mathrm{SO}_{4}$ solutions was studied at $2 \mathrm{C}$. The reaction produces weakly and strongly bound electroadsorbed residues whose formation depends on the adsorption potential, and the electrode surface characteristics. Weakly bound adsorbates are mainily formed on electrodispersed electrodes at potentials higher than $0.1 \mathrm{~V}$ (RHE); strongly bound residues can be removed by setting the electrode in the HER potential range. The presence of molecular oxygen in the electrolyte changes the distribution of adsorbates. The amount of adsorbed residues formed on electrodispersed electrodes is a linear function of the electrode roughness factor. The behaviour of electrodispersed platinum electrodes for glucose electrooxidation can be interpreted in terms of particle size and preferential crystalline orientation effects on the reaction.
\end{abstract}

\section{INTRODUCTION}

The electrooxidation of glucose at platinum electrodes takes place in the entire potential range associated with the thermodynamic stability of bulk water, yielding $\mathrm{CO}_{2}$ and $\mathrm{H}_{2} \mathrm{O}$ as final major products, approaching nearly 100 percent conversion efficiency in neutral or physiological buffered solutions (refs. 1-3). Among other electrooxidation products going into solution, chromatographic and mass spectrommetric analysis revealed that minor amounts of gluconic acld and gluconolactone (refs, 4-6) are also formed. During the reaction strongly adsorbed residues, which behave as real electrocatalytic poisons are also produced. It was recently demonstrated that strongly and weakly adsorbed residues related to the glucose electrooxidation on smooth Pt, can be voltammetrically distinguished. The prevailence of one or the other depends to a great extent on the distribution of the different crystaliine faces at the Pt surface (ref. 7). These results encouraged to investigate the influence of the surface structure of the substrate including possible metal particle size effects on the kinetics of glucose electrooxidation reaction, by using for this purpose electrodispersed Pt electrodes in acid electrolytes (refs. 8-12) which has proved to be useful to study the electrooxidation of ethylene (ref. 13), adsorbed carbon monoxide (ref. 14) and reduced carbon dioxide (ref. 15) under a minimum influence of impurities in solution.

- This manuscript, received in the editorial office of this journal before the Congress, was for some reason not actually presented as a lecture. 


\section{EXPERIMENTAL}

The Pt working electrodes $\left(0.08 \mathrm{~cm}^{2}\right.$ geometric area) consisted of either smooth platinum polycrystalline wires (SPE) (Johnson, Matthey Chem.Co. Specpure) or electrodispersed platinum (EDPE) electrodes prepared according to the two stages procedure already described in the literature (ref. 8), 1.e. the preparation of the hydrous Pt oxide layer, and its subsequent electroreduction. The platinum hydrous oxide layer was made by applying a repetitive symmetric square wave perturbing potential with a halfperiod of $560 \mu s$ between $0.0 \mathrm{~V}$ and $2.4 \mathrm{~V}$ during a time which was adjusted to obtain a preset platinum overlayer roughness factor $(R)$ value. The electroreduction of the platinum hydrous oxide layer was made immediately afterwards by means of a potential scan at $0.001 \mathrm{~V} / \mathrm{s}$ run between $E_{s, a}=1.4 \mathrm{~V}$ and $E_{s, c}=0.0 \mathrm{~V}$. The values of $R$ were in the $20 \leq R \leq 500$ range, and they were determined by comparing the H-adatom monolayer charge resulting from voltammetric runs in $0.5 \mathrm{M} \mathrm{H}_{2} \mathrm{SO}_{4}$ at $0.05 \mathrm{~V} / \mathrm{s}$ between $0.01 \mathrm{~V}$ and $1.40 \mathrm{~V}$, to that of a SPE. A reversible hydrogen electrode (RHE) in the cell solution was used as reference and potentials in the text are referred to RHE. The counter electrode was a ca. $10 \mathrm{~cm}^{2}$ geometric area platinized Pt sheet of the same quality. The $0.5 \mathrm{M} \mathrm{H}_{2} \mathrm{SO}_{4}$ and $0.5 \mathrm{M} \mathrm{HClO}_{4}$ base solutions were prepared by using Mil11Q* (Millipore) water and p.a. chemicals (Merck and Mallinckrodt). Solutions were deaerated by bubbling with nitrogen (99.999\%). Occasionally oxygen previously passed through $98 \% \mathrm{H}_{2} \mathrm{SO}_{4}$ was added to study its influence on glucose electrooxidation.

The electrochemical measurements were made at $30 \mathrm{C}$ by using either a still solution or the microflux cell technique (ref. 16). Triangular sweep voltammetry and open circuit potential decay measurements were performed with a conventional electrochemical setup.

A typical experiment comprised the following stages: i) The stabilized voltammogram between $0.05 \mathrm{~V}$ and $1.5 \mathrm{~V}$ at $0.01 \mathrm{~V} / \mathrm{s}$ was firstly obtained. 1i) Then, the potential was held at $1.5 \mathrm{~V}$ during $10 \mathrm{~s}$ to remove traces of oxidizable impurities from the electrode surface. iii) As the glucose containing solution was flowing, the potential was stepped to

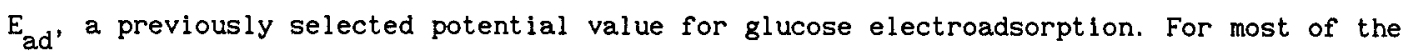
experiments the adsorption time, tad' was fixed at $5 \mathrm{~min}$ except in the case of the electrode with $R=450$ where $t_{\text {ad }}=10 \mathrm{~min}$, in order to achieve surface saturation conditions for the adsorbates. iv) Then, the solution was replaced by base electrolyte, by keeping the working electrode at a constant potential, and subsequently the potential sweep was restarted either in the negative or in the positive direction to electrooxidize the adsorbates directly. In the former case, the electroadsorbate was allowed to react with $\mathrm{H}$ adatoms before its voltammetric electrooxidation take place.

\section{RESULTS AND INTERPRETATION}

\section{Electrooxidation of glucose in $0.5 \mathrm{M} \mathrm{H}_{2} \mathrm{SO}_{4}$}

Blank voltammograms of SPE and EDPE in still $0.5 \mathrm{M} \mathrm{H}_{2} \mathrm{SO}_{4}$ behave similarly for the $\mathrm{H}-$ and O-electroadsorption/electrodesorption reactions as it was already reported (ref. 8) except for the different charge due to EDPE roughness, and to a certain degree of preferred crystalline orientation. The latter can be followed through a change in the relative height of $\mathrm{H}$ adatom electrosorption peaks (Fig. 1). The SPE roughness factor estimated from voltammetry by taking the H-atom monolayer charge as $0.21 \mathrm{mC} / \mathrm{cm}^{2}$ (ref. 17), was 1.9 . 


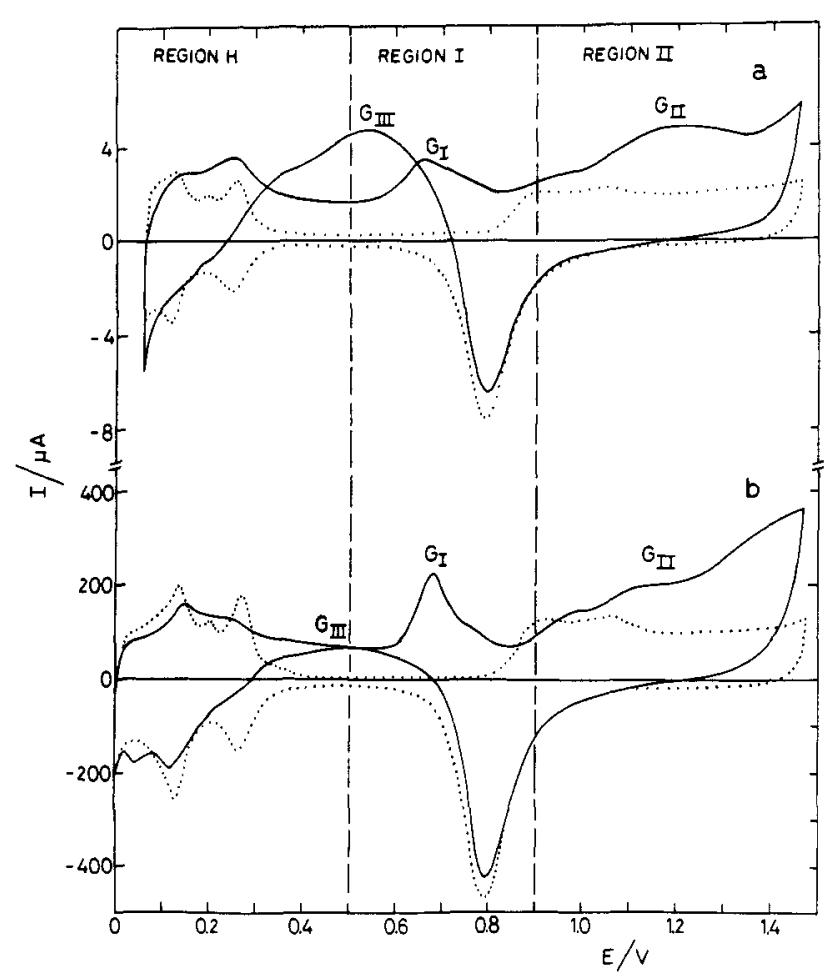

Figure 1 - Cyclic voltammograms for glucose electrooxidation at smooth (a) and electrodispersed (b) platinum electrodes. $0.5 \mathrm{M} \mathrm{H}_{2} \mathrm{SO}_{4}+$ $10^{-2} \mathrm{M}$ glucose, $v=0.01 \mathrm{~V} / \mathrm{s}$. Apparent electrode area $=$ $0.08 \mathrm{~cm}^{2}, R=1.8$ (a), 190 (b) $t=30 \mathrm{C},(\ldots)$ base electrolyte.

On the other hand, the voltammograms for glucose $(G)$ electrooxidation on SPE and EDPE with still solution are considerably different in the H-adsorption/desorption range (region $H$ ), as well as in Region I and II (see Fig. 1). Region I (0.5 V-0.9 V) involves a complex peak $G_{I}$ at ca. $0.70 \mathrm{~V}$ related to glucose electrooxidation with a hump at ca. $0.75 \mathrm{~V}$. Peak $G_{I}$ can be seen more clearly for EDPE. Region II $\left(0.09 \vee\right.$ to $\left.E_{s, a}\right)$ is also related to glucose electrooxidation and to the o-electroadsorption. The latter process is associated with the broad peak $G_{I I}$. When $E_{S, a}=1.4 \mathrm{~V}$, the anodic current for EDPE becomes relatively larger than for SPE. On reversing the potential scan, a reactivation of the glucose electrooxidation mainly caused by glucose readsorption as seen through peak $G_{I I I}$ can be noticed as the PtO layer is gradually electroreduced. The relative contribution of $G_{I I I}$ for EDPE becomes significantly lower than for SPE. When the voltammetric sweep goes into Region H, EDPE shows up a small peak at ca. $0.05 \mathrm{~V}$, which can not be distinguished for SPE.

\section{Electrooxidation of adsorbed residues}

The electrooxidation of glucose residues adsorbed at $E_{\text {ad }}$ was studied by using the microflux cell technique to avoid the readsorption of glucose from the bulk. For $E_{\text {ad }}=0.1 \mathrm{~V}$ (Fig. 2) the appearance of both the double peaked current $\left(R_{I w}\right.$ and $\left.R_{I s}\right)$ and the current $R_{I I}$ overlapping the oxide layer electroformation current $\left(R_{I I}\right)$ suggests that at least two kinds of G-adsorbed residues are formed. The adsorbed species $R_{I}$ is electrodesorbed in region $I$, $1 . e$. , before the Pto formation threshold potential is reached. The corresponding voltammetric response can be resolved into peaks $R_{I W}$ and $R_{I s}$ ' which can be tentatively related to weakly and strongly bound species, respectively. Otherwise, the adsorbed species $R_{I I}$ is electrodesorbed in region II, during the build up of the Pto layer. The electrooxidation of the $R_{I I}$ adsorbate, which can be assigned as the strongest bound species, implies as a broad anodic current peak. At this stage it can be further noted that the stripping voltammogram depends on both the direction of the initial 


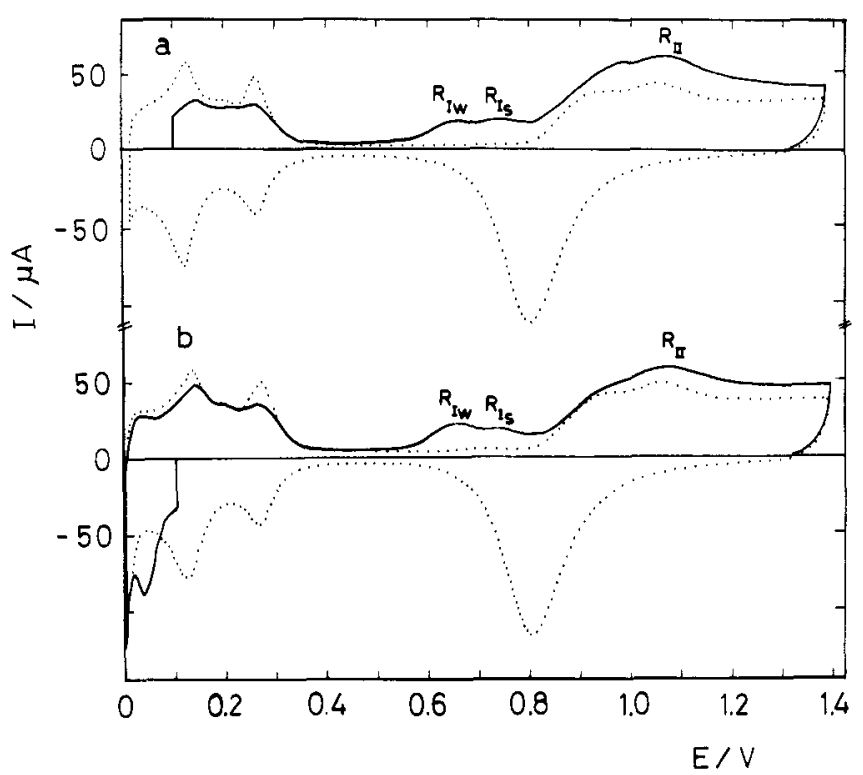

Figure 2 - Flux cell voltammograms for the oxidation of glucose residues formed at $\mathrm{E}_{\mathrm{ad}}=0.1 \mathrm{~V}$ during $300 \mathrm{~s}$ on electrodispersed platinum. Desorption scan started in the positive (a) and in the negative (b) direction.

$0.5 \mathrm{M} \mathrm{H}_{2} \mathrm{SO}_{4}+10^{-2} \mathrm{M}$ glucose, $\mathrm{v}=0.01 \mathrm{~V} / \mathrm{s}$. Apparent electrode area $=0.08 \mathrm{~cm}^{2}$, $R=60, t=30 \mathrm{C},(\ldots)$ base electrolyte.

potential scan (Fig. 2) and on $E_{\text {ad }}$ (Fig. 3). From Figs. (2a) and (2b) it follows that at least a part of $R_{I I}$ disappears when the stripping voltammogram is preceded by a negative potential going scan from $E_{a d}$ to $E_{s, c}$ (Fig. 2b). The partial disappearance of $R_{I I}$ is balanced by the increase in charge of the electroreduction peak observed at ca. $0.05 \mathrm{~V}$ in the negative potential going scan. This fact is consistent with a partial electrochemical hydrogenation and desorption of $R_{I I}$. This reaction can be associated to the cathodic peak at $0.05 \mathrm{~V}$ observed for EDPE.

As $E_{a d}$ is increased (Fig. 3) the electroreduction peak at $0.05 \mathrm{~V}$ tends to disappear in spite of the fact that the anodic peak related to the electrooxidation of $R_{I I}$ becomes significantly smaller. In constrast, the formation of $R_{I}$ residues is enhanced,

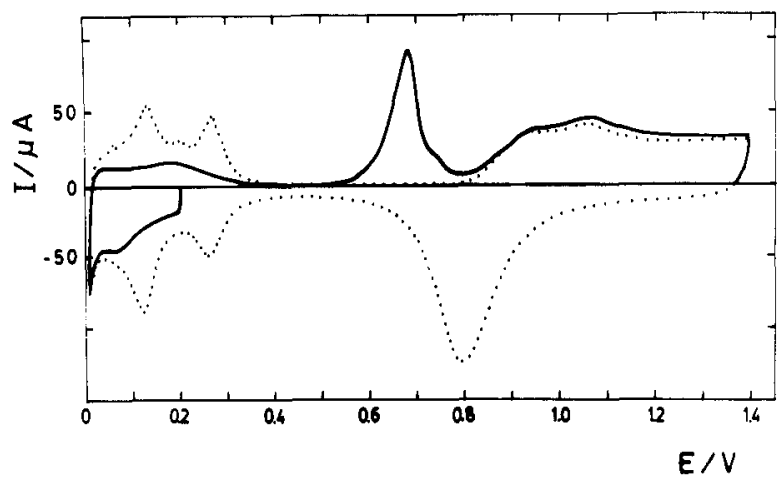

Figure 3 - Flux cell voltammograms for the oxidation of glucose residues formed at $E_{\mathrm{ad}}=0.2 \mathrm{~V}$ during $300 \mathrm{~s}$ on electrodispersed platinum. $0.5 \mathrm{M} \mathrm{H}_{2} \mathrm{SO}_{4}+10^{-2} \mathrm{M}$ glucose, $v=0.01 \mathrm{~V} / \mathrm{s}$. Apparent electrode area $=0.08 \mathrm{~cm}^{2}, R=60$, $t=30 \mathrm{C},(\ldots)$ base electrolyte.

particularly that of $R_{I w}$, as seen through the sharp peak at ca. $0.68 \mathrm{~V}$. It is worth mentioning, that a similar behaviour can also be observed for SPE, but in this case the peak at $0.68 \mathrm{~V}$ becomes smaller and broader. 


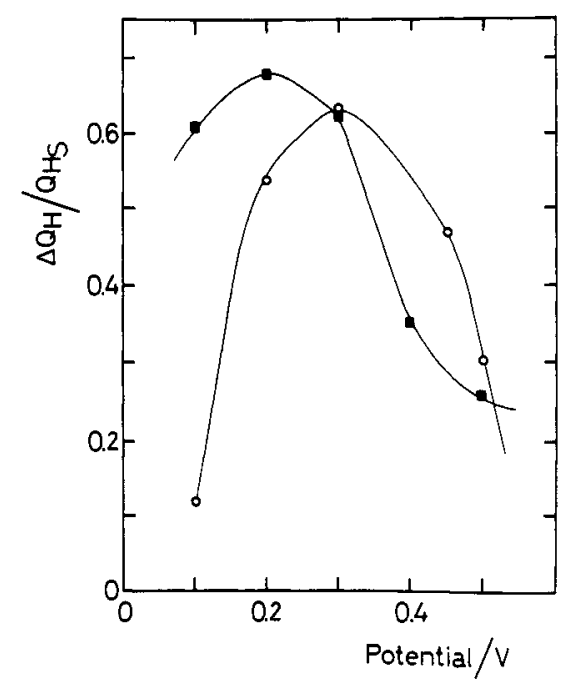

Figure 4 - Surface coverage by glucose adsorbed residues, measured as $\Delta Q_{\mathrm{H}} / \mathrm{Q}_{\mathrm{Hs}}$, vs. $\mathrm{E}_{\text {ad }}$ on smooth (I) and electrodispersed ( 0 ) platinum electrodes. $0.5 \mathrm{M} \mathrm{H}_{2} \mathrm{SO}_{4}+10^{-2} \mathrm{M}$ glucose. Adsorption time = $300 \mathrm{~s}, \mathrm{t}=30 \mathrm{C}$.

From the $\Delta Q_{H} / Q_{\text {Hs }}$ ratio vs. $E_{\text {ad }}$ plot (Fig. 4) the blockage of the electrode surface by adsorbed residues can be inferred. $Q_{H}$ refers to the decrease in the H-electrodesorption voltammetric charge after gluclose adsorption and $Q_{H s}$ to the saturation charge for H-electrodesorption. These plots exhibit a common potential at ca. $0.3 \mathrm{~V}$ where both SPE and EDPE reach the same value for the $\Delta Q_{\mathrm{H}} / \mathrm{Q}_{\mathrm{Hs}}$ ratio. Likewise, at $E_{\text {ad }}<0.3 \mathrm{~V}$ the poisoning by adsorbates of the SPE is greater than that corresponding to EDPE, but for $E_{\text {ad }}>0.3 \mathrm{~V}$ the poisoning effect is reverted. However, for $E_{\text {ad }}>0.5 \mathrm{~V}$ the difference in behaviour between SPE and EDPE tends to disappear. Furthermore, the $R_{I}$ species electrooxidation charge plotted vs. $E_{\text {ad }}$ shows up a bell-shape with a maximum at $0.2 \mathrm{~V}$ for SPE (Fig. 5a) and at $0.3 \mathrm{~V}$ for EDPE (Fig. 5b). Otherwise, for both electrodes, the largest value of the electrooxidation charge related to $R_{I I}$ is obtained at $0.1 \mathrm{~V}$, and it decreases as $E_{\text {ad }}$ increases. It is also interesting to note that a linear relationship between the electrooxidation charge and the roughness factor is obeyed, at least for $R$ values comprised between 1.8 and 450 (Fig. 6).

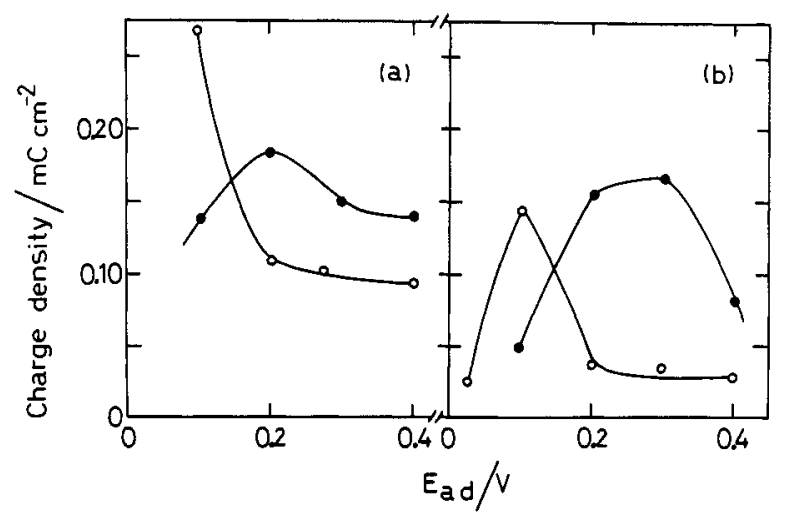

Figure 5 - Electrooxidation charge density of weakly $(0)$ and strongly (o) glucose adsorbed residues on smooth (a) and electrodispersed (b) platinum vs. $\mathrm{E}_{\text {ad }} 0.5 \mathrm{M} \mathrm{H}_{2} \mathrm{SO}_{4}+$ $10^{-2} \mathrm{M}$ glucose. $t_{\text {ad }}=300 \mathrm{~s}, \mathrm{t}=$ $30 \mathrm{C}$.

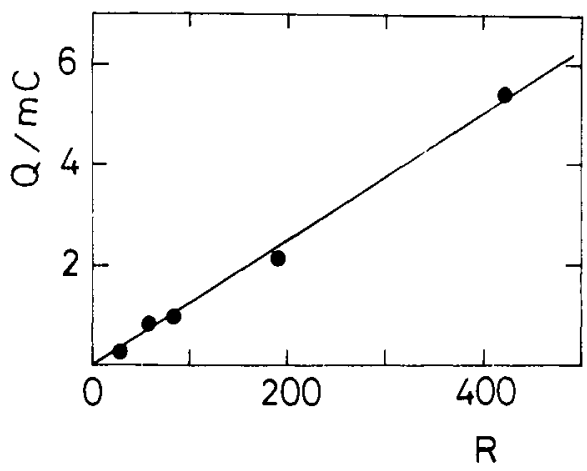

Figure 6 - Electrooxidation charge glucose adsorbed residues vs. rough ness factor plot. Electrodispersed platinum electrodes. $0.5 \mathrm{M} \mathrm{H}_{2} \mathrm{SO}_{4}+$ $10^{-2} \mathrm{M}$ glucose, $\mathrm{v}=0.01 \mathrm{~V} / \mathrm{s}$. Apparent electrode area $=0.08 \mathrm{~cm}^{2}$, $t=30 \mathrm{C}$ 


\section{Electrochemical hydrogenation of adsorbed residues}

Taking into account the fact that a potential excursion in the H-adatom potential region modifies the voltammogram of glucose adsorbed residues electrooxidation (F1g. 1), the influence of electrochemical hydrogenation was investigated by including a potential step in the HER between the glucose electroadsorbed residue formation and its electrochemical stripping. For this purpose the following experimental procedure was followed: i) After attalning the stabilized voltammogram in the base solution, the electrolyte was replaced by the glucose containing solution and the potential was held at $0.1 \mathrm{~V}$ during 5 min to produce glucose adsorbed residues. ii) Then, the base electrolyte was again flowing the potential being stepped to $-0.05 \mathrm{~V}$ during $5 \mathrm{~min}$. 111) Subsequently, the potential was stepped to $0.1 \mathrm{~V}$ and the base solution flow was continued to remove molecular hydrogen from the vicinity of the electrode. iv) Finally, an electrooxidation scan between $0.1 \mathrm{~V}$ and $1.4 \mathrm{~V}$ was applied and the corresponding voltammogram was recorded. This voltammogram (Fig. 7) showed up a noticeable diminution of both $Q_{I I}$ and $Q_{\text {Is }}$. Moreover, the electrooxidation of $Q_{I W}$ was clearly depolarized as the potential of peak $R_{I W}$ appeared at ca. $0.05 \mathrm{~V}$ more negative than in those runs where the preceding strong cathodization was omitted.

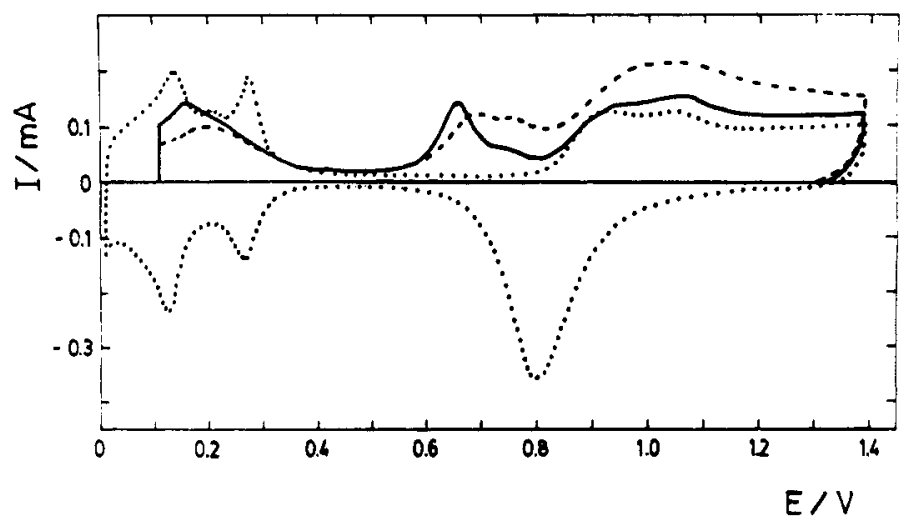

Figure 7 - Voltammograms for the oxidation of adsorbed glucose residues with (-) and without (---) electrochemical hydrogenation treatment described in text.

Electrodispersed platinum electrode. $0.5 \mathrm{M} \mathrm{H}_{2} \mathrm{SO}_{4}+$ $10^{-2} \mathrm{M}$ glucose, $v=0.01 \mathrm{~V} / \mathrm{s}$. Apparent electrode area $=$ $0.08 \mathrm{~cm}^{2}, R=190, t=30 \mathrm{C}$, (...) base electrolyte.

\section{Influence of dissolved oxygen}

It has been reported that oxygen dissolved in the electrolyte solution modifies considerably the nature of the glucose adsorbed residues. Likewise, this effect which depends on the distribution of crystalline faces of the platinum electrode (ref. 7), was also investigated in two different ways. 1) In the first one, the glucose residues were electroadsorbed at $E_{a d}$ during $5 \mathrm{~min}$ from an oxygen saturated glucose containing solution, and then the latter was replaced by base solution. ii) In the second way, glucose residues were formed in the oxygen-free glucose containing solution. Afterwards the base electrolyte was replaced and oxygen was bubbled through during $5 \mathrm{~min}$. Thereafter, the oxygen-containing solution was replaced by fresh deaereated base solution.

Although both procedures furnished comparable results, the voltammograms obtained by adsorbing glucose at $0.2 \mathrm{~V}$ depend whether a SPE or an EDPE was employed. Thus, results obtained for EDPE become practically unaffected by the presence of oxygen dissolved in the electrolyte (Fig. 8), whereas SPE shows a net decrease in the amount of the weakly bound residues which is balanced by an increase of the amount of strongly bound adsorbate (Fig. 9). The latter is accompanied by a slight increase in the charge associated with the $H$ atom electrosorption reactions. 


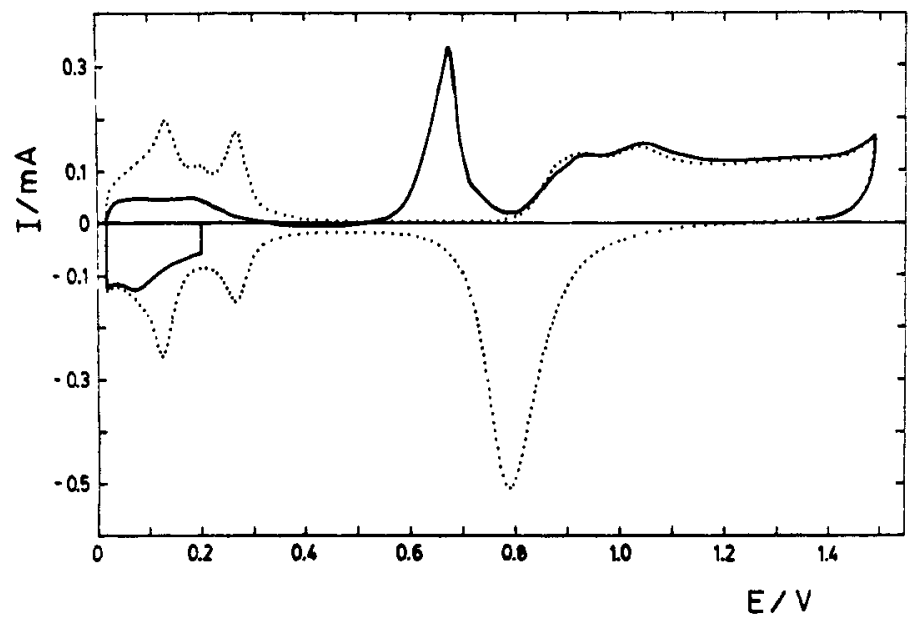

Figure 8 - Voltammograms for the oxidation of adsorbed glucose residues formed at $E_{\text {ad }}=0.2 \mathrm{~V}$ during $300 \mathrm{~s}$ on electrodispersed platinum in $0.5 \mathrm{M} \mathrm{H}_{2} \mathrm{SO}_{4}+10^{-2} \mathrm{M}$ glucose $(-), \mathrm{O}_{2}$ saturated solution, $v=0.01 \mathrm{~V} / \mathrm{s}$. Apparent electrode area $=0.08 \mathrm{~cm}^{2}, R=$ $190, t=30 \mathrm{C},(\ldots)$ base electrolyte.

Figure 9 - Voltammograms for the oxidation of adsorbed glucose residues formed at $E_{a d}=0.2 \mathrm{~V}$ during $300 \mathrm{~s}$ on smooth platinum in $0.5 \mathrm{M} \mathrm{H}_{2} \mathrm{SO}_{4}+10^{-2} \mathrm{M}$ glucose. $\mathrm{O}_{2}$ free (--) and saturated (-) solutions, $v=0.01 \mathrm{~V} / \mathrm{s}$. Apparent electrode area $=0.08 \mathrm{~cm}^{2}, t=30 \mathrm{C}$, (...) base electrolyte.

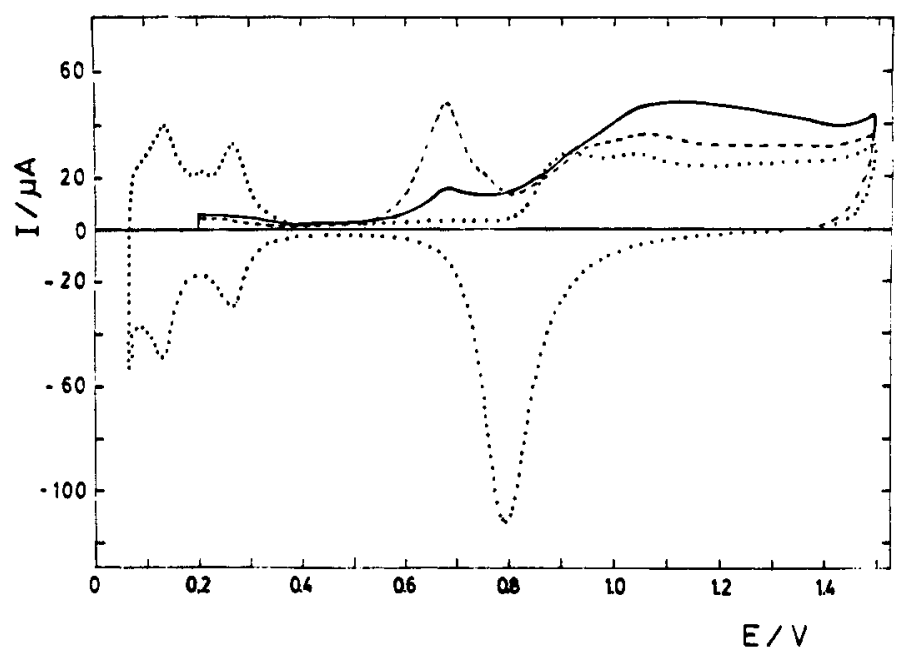

The open circuit potential evolution due to the reaction between dissolved oxygen and glucose adsorbed residues was also studied by forming the electroadsorbate during $5 \mathrm{~min}$ at $E_{a d}=0.2 \mathrm{~V}$ and subsequently, the electric circuit was opened in base solution and oxygen was kept bubbling slowly into the cell. Under these circumstances the corresponding potential transients exhibit a potential arrest (Fig. 10) which oscillates between $0.575 \mathrm{~V}$ and $0.625 \mathrm{~V}$ and depends on the oxygen bubbling conditions.

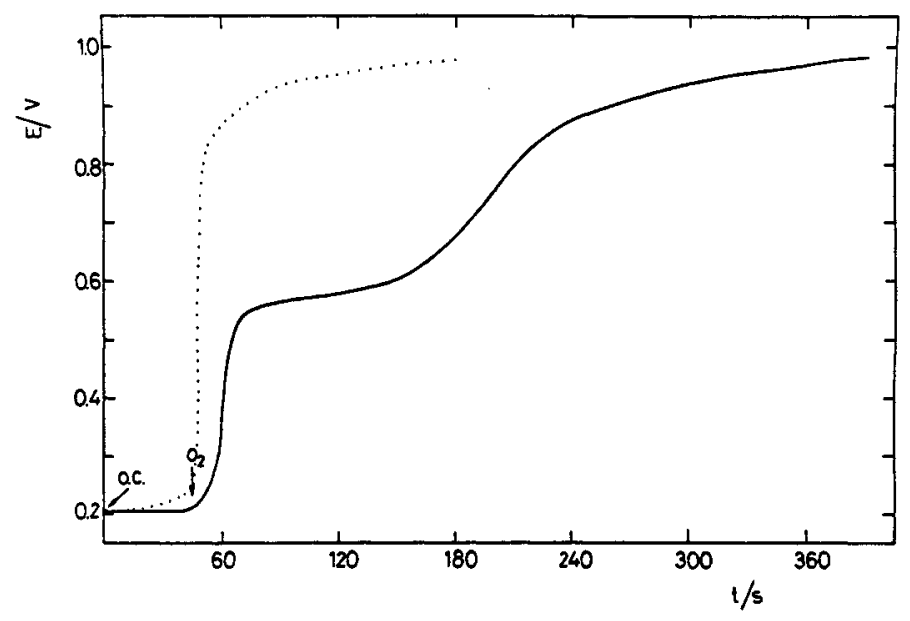

Figure 10 - Open circuit potential evolution of smooth platinum electrode in $0.5 \mathrm{M} \mathrm{H}_{2} \mathrm{SO}_{4}$ during the bubbling of $\mathrm{O}_{2}$. Platinum surface covered ( -) and uncovered (...) by glucose residues previously adsorbed from a $0.5 \mathrm{M} \mathrm{H}_{2} \mathrm{SO}_{4}+10^{-2} \mathrm{M}$ glucose solution at $E_{\text {ad }}=0.2 \mathrm{v}$ during $300 \mathrm{~s}$. Apparent electrode area $=1.2 \mathrm{~cm}^{2}$, $t=30 \mathrm{C}$. 


\section{DISCUSSION}

The voltammetric electrooxidation of glucose residues on electrodispersed platinum becomes very sensitive to the electrode surface characteristics, the solution composition and the direction of the voltammetric sweep started immediately after the glucose-electroadsorption step (Figs. 1 and 2) (refs. 7,18). Broadly considered the voltammograms on electrodispersed Pt exhibit two well-defined electrooxidation regions comparable to those already reported for the case of preferred crystalline oriented platinum (pco) Pt surface (ref. 6). Glucose electrooxidation on pc and pco Pt was interpreted by assuming that at least two kinds of adsorbed residues presumably related to different adsorption energies sites on $\mathrm{Pt}$ can be formed in the course of the reaction, those residues conveying to the formation of poisoning species with different bonding strengths. The mechanistic aspects of the corresponding reactions were extensively discussed in a previous work (ref. 7).

The glucose residue electrooxidation on electrodispersed platinum exhibits a clear enhancement of the charge contribution due to weakly bound adsorbed residues. This effect can be directly assigned to the proper topography of this type of electrodispersed electrodes which as deduced from STM (refs. 10,11,19) and X-ray diffractometry (ref. 8) consists of metal clusters and voids of ca. $10 \mathrm{~nm}$ average diameter resulting in a sort of brush-like structure with a certain preferred crystalline orientation. This rough structure appears to be accessible to glucose residues even for values of $R=450$ (Fig. 7) without any appreciable pore diffusion effects at least in the potential sweep rate used in the present work. This large active surface accessibility of electrodispersed $P t$ electrodes was earlier proved for the electroadsorbate produced from smaller molecules such as $\mathrm{CO}$ (ref. 14) and $\mathrm{CO}_{2}$ (ref. 15). Nevertheless, for glucose residues the maximum coverage is smaller than those resulting for either $\mathrm{CO}$ or reduced $\mathrm{CO}_{2}$ adsorbates. This difference suggests that the initial adsorption of glucose molecule preceding its electroadsorption likely requires a number of neighbour adsorption sites which is greater than that needed for the electroadsorption of smaller molecules. It is reasonable to expect that glucose electroadsorption should involve the formation of a variety of species depending on the degree of fragmentation of the molecule reached during electroadsorption. Therefore, the distribution and structure of the different adsorbates should determine the number of free sites on $\mathrm{Pt}$ which become available for $\mathrm{H}$ atom electroadsorption. Whether the electrooxidation of the different fragments originates different reaction products or they go mainly directly to $\mathrm{CO}_{2}$, is a matter which is open to further research, because in the present circumstances neither qualitative nor quantitative evaluations of the reaction products could be made for such small amounts as those produced in a few voltammetric cycles.

The electrochemical hydrogenation of adsorbed residues produced by scanning the potential negatively from $E_{\text {ad }}$ preceding the electrooxidation scan, affects considerably the voltammetric response of the strongly bound adsorbate, whereas the weakly adsorbed one remains on the surface. In this case the behaviour of the $G_{R I, w}$ species appears to be similar to that exhibited by poisons produced on Pt from $\mathrm{CO}$, reduced $\mathrm{CO}_{2}, \mathrm{CH}_{3} \mathrm{OH}$, and other simple organic fuels on $P t$ which in turn can not be removed by electrochemical hydrogenation. The hydrogenation reaction produces a drastic decrease in the electrooxidation charge associated with poisons after setting the electrode at a potential in the HER potential range, and that reaction can be probably related to the cathodic current peak observed at ca. $0.030 \mathrm{~V}$ on electrodispersed Pt. 
It is known that the $G_{R I}$ species which remain practically unchanged on smooth platinum after a drastic cathodization in the $H$ adatom potential range, can be oxidized at relatively low potentials when $\mathrm{O}_{2}$ is dissolved in the solution, presumably leaving free sites on the electrode surface. This type of reaction was already postulated for the removal of $\mathrm{CO}_{\text {ad }}$ by $\mathrm{O}_{2}$ through the $\mathrm{H}_{2} \mathrm{O}_{2}$ resulting from $\mathrm{O}_{2}$ electroreduction. For the case of $\mathrm{CO}$ adsorbate the following reaction was postulated (ref. 29):

$$
\mathrm{CO}_{\mathrm{ad}}+\mathrm{H}_{2} \mathrm{O}_{2}=\mathrm{CO}_{2}+\mathrm{H}_{2} \mathrm{O}
$$

The efficiency of this reaction depends on the amount of $\mathrm{H}_{2} \mathrm{O}_{2}$ formed at the electrode. For platinized platinum electrodes the amount of $\mathrm{H}_{2} \mathrm{O}_{2}$ is very small and consequently its influence can hardly be observed (ref. 20). For the case of glucose electroadsorbed residues, the possible formation of $\mathrm{H}_{2} \mathrm{O}_{2}$ as oxidation agent can be postulated by considering the possibility that free sites for $\mathrm{O}_{2}$ electroreduction are influenced by the chemisorption of organic residues (ref. 20), as seen from the $H$ adatom residual charge which appears to be greater than in the case of CO adsorbate. Furthermore, for smooth $\mathrm{Pt}$ the $G_{R I}$ adsorbate in the presence of $O_{2}$ yields $G_{R I I}$ adsorbate as seen through the voltammograms depicted in Fig. 9. This change which can be assoclated with an interconversion reaction is not, in principle, observable at least for the time scale of the present experiments with electrodispersed Pt electrodes. The low electrocatalytic activity of electrodispersed electrodes in the presence of $\mathrm{O}_{2}$ dissolved in solution, is similar to that found for (111)-type pco Pt with a roughness factor of ca. 5 . This means that in the case of electrodispersed electrodes there is an influence of the crystalline orientation which also contributes to enhance the stability of weakly bound glucose adsorbed residues when molecular oxygen is present in the solution.

\section{CONCLUSIONS}

The electrodispersed platinum electrodes, obtained by the reduction of thick hydrous $\mathrm{Pt}$ oxide layers, are promising glucose electrooxidation catalysts. The linear dependence of the electrooxidation charge vs. the electrode roughness factor indicates a relatively low mass transport resistance through the rough metal structure at least for an active area increase up to about five hundred fold. On the other hand, the surface characteristics of the EDPE favours the preferred formation of weakly bound adsorbates from glucose. This adsorbate reacts with oxygen dissolved in the electrolyte ylelding a strongly bound adsorbate. This fact is interesting for possible applications of this type of electrodes in fuel cells for medical purposes. Otherwise, the strongly bound adsorbed residues can be removed from the EDPE by electrochemical hydrogenation through the formation of adsorbed H-atoms.

\section{Acknowledgement}

This research project was financially supported by the Consejo Nacional de Investigaciones Cientificas $y$ Técnicas (CONICET) and the Comision de Investigaciones Cientificas de la Provincia de Buenos Aires (CIC). This work was also partially supported by the Regional Program for the Scientific and Technological Development of the Organization of the American States. A.E.B. is member of the Research Career of CIC.

\section{REFERENCES}

1. V. Gebhardt, G. Luft, G.J. Richter and F. Von Sturm, Bioelectrochem. Bioenerg., 607-624 (1978).

2. H. Lerner, J.S. Soeldner, C.K. Colton and J. Giner, Diabetes Care, 5, 229-237 (1982).

3. J.R. Rao, G.S. Richter, F. von Stum and E. Weidlich, Bioelectrochem. Bioenerg., 3 , 139-150 (1976) 
4. M. L. B. Rao and R. Drake, J.Electrochem. Soc., 116, 334-337 (1969).

5. S. Ernst, J. He1tbaum and C. H. Hamann, Ber. Bunsenges Phys. Chem., 84, 50-56 (1980).

6. A.E. Bolzan, T. I wasita and W. Vielstich, J.Electrochem. Soc., 134, 3052-3058 (1987).

7. A.M. Castro Luna, A.E. Bolzan, M.F.L. de Mele and A.J. Arvia, Z. Phys. Chem., 160, 25-43 (1988).

8. A.C. Chialvo, W.E. Triaca and A.J. Arvia, J.Electroanal.Chem., 146, 93-108 (1983).

9. A.E. Bolzan, A.M. Castro Luna, A. Visintin, R.C. Salvarezza and A.J. Arvia, Electrochim. Acta, 33, 1743-1751 (1988).

10. L. Vásquez, J. Gómez, A.M. Baró, N. García, M.L. Marcos, J. González-Velasco, J.M. Vara, A.J. Arvia, J. Presa, A. Garcia and M. Aguilar, J.Am.Chem. Soc., 109, 1730-1733 (1987).

11. C. Alonso, R.C. Salvarezza, J.M. Vara, A.J. Arvia, L. Vazquez, A. Bartolomé and A.M. Bar6, J. Electrochem. Soc., 137, 2161-2165 (1990).

12. L. Vázquez, A. Bartolomé, A.M. Baro, C. Alonso, R.C. Salvarezza and A.J. Arvia, Surf.Sci., 215, 171-189 (1989).

13. S.M. Piovano, A.C. Chialvo, W.E. Triaca and A.J. Arvia, J.Appl.Electrochem., 17, 147-155 (1987).

14. A.M. Castro Luna, M.C. Giordano and A.J. Arvia, J.Electroanal. Chem., 259, 173-187 (1989).

15. M. L. Marcos, J.M. Vara, J. González-Velasco and A.J. Arvia, J.Electroanal.Chem., 224, 189-198 (1987).

16. P. Stonehart and G. Kohlmeyr, Electrochim. Acta, 17, 369-382 (1972).

17. T. Blegler, D. A. J. Rand and R. Woods, J.Electroanal. Chem., 29, 269-277 (1971).

18. M.F.L. de Mele, H.A. Videla and A.J. Arvia, J.Electrochem. Soc, 129, 2207-2213 (1982).

19. J. Gómez, L. Vázquez, A.M. Baró, N. García, C. L. Perdriel, W.E. Triaca and A.J. Arvia, Nature, 323, 612-614 (1986).

20. M.W. Breiter, J.Electroanal, Chem., 127, 157-169 (1981). 